\title{
OBITUARY
}

\section{OTTO BARKAN}

Surgeons all over the world will regret the death of Otto Barkan on April 26, 1958, at the age of 71. He was the son of Dr. Adolph Barkan, a Hungarian who was one of the original staff in the Eye, Ear, Nose and Throat Department of Stanford University School of Medicine. The son followed in the footsteps of his father, and in his medical education he travelled widely. He studied at Trinity College, Oxford, obtained the B.A. degree in 1909, graduated in medicine in Munich in 1914, and later served as a house-physician in St. Mary's Hospital, London, and became a member of the Royal College of Surgeons of England. His essential eye training was received at Munich and Vienna. Returning to San Francisco in 1920, he became a member of the Faculty at Stanford University where he worked for the remainder of his professional life, practising ophthalmology in San Francisco. He gained a world-wide reputation by his studies on glaucoma and was a pioneer in stressing the importance of the width of the angle of the anterior chamber in the differential diagnosis between closed-angle and simple glaucoma. He will always be remembered for the introduction of the operation of goniotomy (trabeculotomy) in the congenital form of this disease, a technique which has revolutionized the prognosis of this intractable condition in many cases.

In his life-time, Otto Barkan's achievements were duly recognized and his professional interests and contacts were world-wide; apart from being a member of many American Societies, he was a member of the British, French, and Belgian Ophthalmological Societies. He was also a keen sportsman; he rowed for Oxford University and was an ardent skier and Alpinist. A delightful companion, a courteous host and an enthusiastic colleague, he will be much missed by his many friends all over the world.

\section{HENRY KIRKPATRICK}

Ophthalmologists particularly in Great Britain and in India will be sad to hear of the death of Lt.-Col. H. Kirkpatrick, who spent most of his life in the Indian Medical Service. He died peacefully at his home in Hampshire on May 11, 1958, at the age of 86.

Educated in Dublin, where he qualified in 1894, he did his postgraduate work in St. Mark's Eye and Ear Hospital in that city under the instruction of Swanzy and Werner. In 1898 he joined the Indian Medical Service and was appointed to the staff of the General Hospital, Madras, where he acted as physician and professor of pathology. There he came under the influence of Col. R. H. Elliott, whom he succeeded in 1914 as Superintendent of the Government Ophthalmic Hospital and Professor of Ophthalmology in Madras. While in this office he supervised the construction of the Elliot School, a large teaching institution, and spent much of his time in improving the facilities for postgraduate training particularly in pathology. Leaving Madras in 1920, he started consulting practice in London, again initially in association with Elliot, becoming ophthalmic surgeon to the Hospital for Tropical Diseases, and lecturer in ophthalmology at the London School of Hygiene and Tropical Medicine. In 1937 he gave up consulting practice and retired to live in the country in Hampshire.

Kirkpatrick was an excellent ophthalmologist, an accomplished surgeon, and a conscientious teacher. His greatest achievement was the advancement of ophthalmology in South India where many of his old pupils will regret his death. He made a considerable number of contributions to ophthalmic literature, published two small volumesCataract and its Treatment (1921) and Diseases of the Eye (1936) - and collaborated with Elliot in the production of his standard textbook-Tropical Ophthalmology (1920). A kindly, unassuming, and courteous man, he was beloved by all who came in contact with him. He is survived by a wife and two daughters. 